\title{
Analysis of a Questionnaire Survey regarding Current Conditions against Exposure to Anticancer Drugs and Reports of Cancer Chemotherapy at Outpatient Departments in Japan
}

\author{
Tsuyoshi Shirakawa1,2, Tomoko Hara ${ }^{3}$, Kojiro Hata ${ }^{4}$, Kimitaka Suetsugu, Hideki Kakimoto5, \\ Kentaro Ogata6, Yousuke Ikari', Hidenori Sasaki ${ }^{7}$, Makoto Takahashi', Masaru Fukahori ${ }^{9}$, \\ Miyuki Uoi ${ }^{10}$, Taito Esaki11, Mikako Hiraike ${ }^{12}$, Toshinobu Hayashi'2, Akira Tokunaga ${ }^{13}$, \\ Norio Ureshino ${ }^{14}$, Tsuneo Kuwamura ${ }^{15}$, Hitoshi Kusaba' ${ }^{16}$, Kenji Mitsugi' ${ }^{17}$ Eishi Baba ${ }^{1{ }^{*}}$ \\ ${ }^{1}$ Department of Oncology, Miyazaki Prefectural Miyazaki Hospital, Miyazaki, Japan \\ ${ }^{2}$ Department of Internal Medicine, Fukuoka Wajiro Hospital, Fukuoka, Japan \\ ${ }^{3}$ Department of Pharmacy, Hamanomachi Hospital, Fukuoka, Japan \\ ${ }^{4}$ Department of Pharmacy, Kyushu University Hospital, Fukuoka, Japan \\ ${ }^{5}$ Department of Pharmacy, Fukuoka University Hospital, Fukuoka, Japan \\ ${ }^{6}$ Department of Practical Pharmaceutical Science, Faculty of Pharmaceutical Sciences, Fukuoka University, Fukuoka, Japan \\ ${ }^{7}$ Division of Medical Oncology, Hematology, and Infection Diseases, Fukuoka University Hospital, Fukuoka, Japan \\ ${ }^{8}$ Department of Pharmacy, Kurume University Hospital, Fukuoka, Japan \\ ${ }^{9}$ Division of Gastroenterology, Kurume University Department of Medicine, Fukuoka, Japan \\ ${ }^{10}$ Department of Pharmacy, National Kyushu Cancer Center, Fukuoka, Japan \\ ${ }^{11}$ Department of Gastrointestinal and Medical Oncology, National Kyushu Cancer Center, Fukuoka, Japan \\ ${ }^{12}$ Department of Pharmacy, National Hospital Organization Kyushu Medical Center, Fukuoka, Japan \\ ${ }^{13}$ Department of Pharmacy, Saga-Ken Medical Centre Koseikan, Saga, Japan \\ ${ }^{14}$ Department of Medical Oncology, Saga-Ken Medical Centre Koseikan, Saga, Japan \\ ${ }^{15}$ Department of Pharmacy, Japan Community Healthcare Organization Kyushu Hospital, Fukuoka, Japan \\ ${ }^{16}$ Department of Medicine and Comprehensive Biosystemic Science, Kyushu University Graduate School of Medical Sciences, \\ Fukuoka, Japan \\ ${ }^{17}$ Department of Medical Oncology, Hamanomachi Hospital, Fukuoka, Japan \\ ${ }^{18}$ Department of Comprehensive Clinical Oncology, Faculty of Medical Sciences, Kyushu University, Fukuoka, Japan \\ Email: *e-baba@c-oncology.med.kyushu-u.ac.jp
}

How to cite this paper: Shirakawa, T., Hara, T., Hata, K., Suetsugu, K., Kakimoto, H., Ogata, K., Ikari, Y., Sasaki, H., Takahashi, M., Fukahori, M., Uoi, M., Esaki, T., Hiraike, M., Hayashi, T., Tokunaga, A., Ureshino, N., Kuwamura, T., Kusaba, H., Mitsugi, K. and Baba, E. (2017) Analysis of a Questionnaire Survey regarding Current Conditions against Exposure to Anticancer

\begin{abstract}
[Background] Medical staff have many occasions to be exposed to anticancer drugs (ACDs) in the process of performing cancer chemotherapy. Although guidelines for the safe handling of ACDs have been published, actual measures against exposure to ACDs differ between hospitals, and no surveillance data regarding the conditions of each hospital in relation to performing che-
\end{abstract}


Drugs and Reports of Cancer Chemotherapy at Outpatient Departments in Japan. Pharmacology \& Pharmacy, 8, 140-152. https://doi.org/10.4236/pp.2017.85010

Received: April 13, 2017

Accepted: May 19, 2017

Published: May 22, 2017

Copyright (c) 2017 by authors and Scientific Research Publishing Inc. This work is licensed under the Creative Commons Attribution International License (CC BY 4.0).

http://creativecommons.org/licenses/by/4.0/

Open Access motherapy in Japan are available. [Methods] To understand current measures against exposure to ACDs and problems related to cancer chemotherapy at outpatient departments, we conducted a questionnaire survey on doctors, pharmacists, and nurses in 10 leading hospitals for cancer chemotherapy in Japan. [Results] Responses were received from all 10 institutions. The hospital pharmacists prepared all ACDs for outpatients in each institution. All hospitals took basic measures against ACD exposure, such as using personal protective equipment and penetration-resistant waste containers. Conditions against exposure to ACDs generally improved between 2012 and 2015, especially in terms of conveyance of ACDs and use of a closed-system drug transfer device. However, no measures linking ACDs with administration routes or injection sites were commonly taken in any of the hospitals in 2015. [Conclusions] Conditions against ACD exposure improved between 2012 and 2015, possibly because new guidelines were issued. To improve measures for ACD exposure in Japan, preparing more appropriate manuals and offering more opportunities to medical staff for continuing education are considered important.

\section{Keywords}

Exposure, Anticancer Drugs, Measurement, Personal Protective Equipment, Outpatient Service

\section{Introduction}

Cancer is one of the leading causes of morbidity and mortality worldwide [1]. In 2014, malignant neoplasms were responsible for 368,103 deaths, making it the most common cause of death in Japan [2]. The number of deaths due to malignant neoplasms has been increasing, and this trend is expected to continue. Based on recent progress in cancer chemotherapy, a variety of new anticancer drugs (ACDs) have been developed; however, this has led to an increasing chance of exposure to ADCs for medical staff such as doctors, nurses, and pharmacists.

The widely used concept of hazardous drugs (HDs) was first proposed in 1990 by the American Society of Health-System Pharmacists [3]. In 2004, the National Institution of Occupational Safety and Health (NIOSH) implemented what is referred to as the "NIOSH Alert" to increase awareness regarding exposure to HDs [4]. ACDs are considered HDs, and ACDs in the wider sense include cytotoxic drugs, molecular-targeted agents, hormonal therapy drugs and immunotherapeutic agents. Adverse events resulting from occasional exposure to ACDs are classified as biological and health influences [5] [6] [7] [8] [9]. Occupational exposure mainly occurs in the preparation, transportation, administration and disposal processes, and various types of occupations are associated with each process. Therefore, the importance of taking measures to prevent occasional ACD exposure has been recognized.

In the U.S., guidelines for the proper handling of ACDs were published by the Occupational Safety and Health Administration in 1986 [10], the American So- 
ciety of Health-System Pharmacists (ASHP) in 1990 [3], the Oncology Nursing Society in 2003 [5], NIOSH in 2004 [4], and the International Society of Oncology Pharmacy Practitioners in 2007 [11]. In addition, both the Japan Society of Hospital Pharmacists and the Japan Nursing Association have discussed ways of handling, and taken measures against ACD exposure since 1991. Furthermore, the Ministry of Health, Labour and Welfare in Japan established an additional medical fee in 2010 when hospitals started using a closed-system drug transfer device (CSTD) in preparation for ACDs.

This background shows that measures against ACD exposure among medical staff have been promoted, and this has led to increased awareness in Japan. However, the actual condition of measures against ACD exposure in each hospital that performs cancer chemotherapy in Japan remains unclear because no surveillance data have been available, especially in the English literature. Therefore, we conducted a questionnaire survey regarding the current condition of measures against $\mathrm{ACD}$ exposure in cancer chemotherapy and compared the results from 2015 with those from 2012.

\section{Methods}

\subsection{Survey Participants}

We conducted a questionnaire survey on medical doctors, pharmacists, nurses and lawyers from 10 hospitals in the Kyushu and Yamaguchi region that are part of the multidisciplinary Fukuoka Medical Oncology Group-Kyushu Yamaguchi Total Oncology Group (FMOG-KYTOG). In these 10 hospitals, patients receive cancer chemotherapy as inpatients or outpatients. Responses were received from all 10 hospitals, which included two core prefectural hospitals and six core local hospitals. Multiple choice questions were used to help eliminate potential sources of bias and arbitrariness. All participants were informed that their participation in the present study was voluntary. Certified specialists, including medical oncologists, clinical pharmacists, and nurses, were selected to participate. The number of participating hospitals differed in each survey because the sample size was based on the number of participants in the FMOG-KYTOG who were able to respond to the survey.

\subsection{Survey Timing}

The first survey was conducted in February 2012 on pharmacists from eight FMOG-KYTOG hospitals as an actual condition survey regarding measures against exposure to ACDs in preparing for injections. The second survey was conducted in May 2012 on doctors and nurses from 18 divisions in six FMOGKYTOG hospitals regarding measures against exposure to ACDs during administration. The final survey was conducted in August 2015 on nurses and pharmacists from 10 FMOG-KYTOG hospitals regarding measures against exposure to ACDs during administration and the current conditions and problems of the ambulatory treatment unit (ATU). About 15 participants were enrolled in each survey. 


\subsection{Survey Contents}

Question items in the survey regarding preparation for ACD injections concerned the following: ACD preparation conditions (subjects, cases, occupations, holiday correspondence, environment and devices), measures against ACD exposure during preparation, abolition conditions, and cleaning conditions at the facility. Question items regarding the administration of ACD injections concerned the following: hospital manuals, means of conveyance, equipment, use of tools or goods, abolition conditions, and how to deal with patients. Question items regarding the actual current conditions and problems of the ATU concerned the following: current conditions and hopes of the ATU, administration equipment, use of tools or goods, abolition conditions, and preparation by pharmacists. The contents of survey were not standardized. The validity and reliability of the questionnaire were not tested, so the questions, statements, and answers were constructed and revised by certified specialists. The questionnaire was designed by certified medical oncologists and clinical pharmacists from the FMOG-KYTOG. The questionnaires were anonymous and responses were returned in sealed envelopes. Data were compiled following the ethical principles of the Declaration of Helsinki. Participation in the study was strictly voluntary, and appropriate care was taken to protect all personal information.

\section{Results}

Survey of pharmacists regarding measures against exposure during preparation for ACD injections in 2012.

\subsection{Preparation for ACD Injections and Number of Monthly Cases}

The current conditions regarding preparation for ACD injections by pharmacists within one month in 2012 were surveyed. Answers were collected from pharmacists in all eight of the participating hospitals (response rate, 100\%). Pharmacists prepared ACDs for all patients in seven hospital outpatient and six hospital inpatient departments. Pharmacists from other hospitals also prepared ACDs for most of the patients. Pharmacists from four hospitals prepared ACDs on holidays. In these four hospitals, ACD preparation was only performed by pharmacists. ACDs were occasionally prepared by doctors at four hospital inpatient departments, and by nurses at one hospital outpatient department. The numbers of cases involving ACD preparation at all hospital inpatient and outpatient departments are shown in Table 1.

\subsection{Condition of the Environment and Equipment during Preparation or Audit}

Environmental factors for the preparation of ACDs were surveyed (Table 1). ACDs were prepared in an exclusive room in the department of pharmacy within all hospitals. Preparation involved the use of class II biological safety cabinets (BSCs) in all hospitals. Seven hospitals used an exhaust system for outside ventilation. During preparation, masks, gowns, and gloves were used in all hospitals. 
Table 1. Survey of pharmacists on current conditions regarding measures against exposure druing preparation of injections of anticancer drugs in 2012.

\begin{tabular}{|c|c|c|c|}
\hline \multirow{2}{*}{\multicolumn{2}{|c|}{ Question items }} & \multicolumn{2}{|c|}{$\mathrm{n}=8$ (Hospitals) } \\
\hline & & Median & Range \\
\hline \multicolumn{2}{|l|}{ Beds for inpatient service } & 459 & $400-1275$ \\
\hline \multicolumn{2}{|c|}{ Number of monthly preparation cases at outpatient services } & 345.5 & $70-1000$ \\
\hline \multirow{2}{*}{\multicolumn{2}{|c|}{ Number of monthly preparation cases at inpatient services }} & 372 & $25-1000$ \\
\hline & & no. & $\%$ \\
\hline \multicolumn{2}{|c|}{ Preparation for all patients by pharmacist at outpatient services } & 7 & 87.5 \\
\hline \multicolumn{2}{|c|}{ Preparation for all patients by pharmacist at inpatient services } & 6 & 75 \\
\hline \multicolumn{2}{|l|}{ Preparation by doctor } & 3 & 37.5 \\
\hline \multicolumn{2}{|l|}{ Preparation by nurse } & 1 & 12.5 \\
\hline \multicolumn{2}{|l|}{ Preparation by pharmacist on holidays } & 4 & 50 \\
\hline \multicolumn{2}{|l|}{ Preparation in an exclusive use room } & 8 & 100 \\
\hline \multicolumn{2}{|l|}{ Use of BSCs } & 8 & 100 \\
\hline \multicolumn{2}{|l|}{ Use of class II BSCs } & 8 & 100 \\
\hline \multicolumn{2}{|l|}{ Use of class III BSCs } & 0 & 0 \\
\hline \multicolumn{2}{|l|}{ Outside exhaust system } & 7 & 87.5 \\
\hline \multicolumn{2}{|l|}{ Cleaning BSCs every day } & 8 & 100 \\
\hline \multirow{2}{*}{ Method of cleaning BSCs* } & by alcohol & 8 & 100 \\
\hline & by wet wiping & 4 & 50 \\
\hline \multicolumn{2}{|l|}{ BSC idling before and after use } & 6 & 75 \\
\hline \multirow{5}{*}{ Equipment at preparation ${ }^{*}$} & Hair cover & 3 & 37.5 \\
\hline & Mask & 8 & 100 \\
\hline & Gown & 8 & 100 \\
\hline & Goggles & 2 & 25 \\
\hline & Gloves & 8 & 100 \\
\hline \multirow{3}{*}{ Material of gloves at preparation ${ }^{*}$} & Nitrile & 6 & 75 \\
\hline & Latex & 3 & 37.5 \\
\hline & Plastic & 1 & 12.5 \\
\hline \multicolumn{2}{|l|}{ Double-use of gloves at preparation } & 7 & 87.5 \\
\hline \multicolumn{2}{|l|}{ Use of CSTD at preparation } & 5 & 62.5 \\
\hline \multirow{2}{*}{ Recapping* } & Weighing & 8 & 100 \\
\hline & Exhaustion & 7 & 87.5 \\
\hline \multirow{3}{*}{ Equipment at audit* } & Mask & 1 & 12.5 \\
\hline & Glove & 2 & 25 \\
\hline & No answer & 5 & 62.5 \\
\hline \multicolumn{2}{|c|}{ Exhausion of glass vials or ampuls in a sealed plastic bag } & 8 & 100 \\
\hline \multicolumn{2}{|c|}{ Exhausion of glass vials or ampuls into an exclusive-use container } & 8 & 100 \\
\hline Priming by pharmacists & & 1 & 12.5 \\
\hline & Water-wet & 5 & 62.5 \\
\hline Wining for pronorotion of room flockt & Dry-cloth & 1 & 12.5 \\
\hline & $\mathrm{NaOH}$ & 1 & 12.5 \\
\hline & Not performed & 2 & 25 \\
\hline
\end{tabular}

BSC, biological safety cabinet; CSTD, closed-system drug transfer device; *, multiple answers allowed. 
Three hospitals also used hair covers, and two others used goggles. Double-use of gloves made of nitrile, latex, or plastic was used in seven hospitals. A CSTD was used during ACD preparation in five hospitals, and the types of drugs used were cyclophosphamide, ifosfamide, and bendamustine. ACDs were recapped or exhausted during weighing in all and seven hospitals, respectively. All hospitals exhausted glass vials and ampuls of ACDs into sealed plastic bags after preparation. ACDs were exhausted into exclusive containers in all hospitals. Pharmacists in one hospital primed ACDs, pharmacists in another hospital used gloves and masks during the auditing process, and two other hospitals used gloves.

\subsection{Cleaning Environment}

Cleaning was performed every day in all hospitals (Table 1). Alcohol was used for cleaning BSCs in all hospitals, and wet wiping (wiping after being soaked in water) was additionally performed in four hospitals. Idling of BSCs was performed before and after use in six hospitals. The floor of the preparation room was cleaned in six hospitals: wet wiping was used in five hospitals and dry-cloth wiping was used in one. Moreover, $0.3 \%$ sodium hydroxide was used in one hospital.

Survey of doctors and nurses regarding measures against exposure during ACD administration in outpatients in 2012.

\subsection{Measures against Exposure during Conveyance or Administration of ACDs}

Answers were collected from clinical oncologists or pharmacists in all six of the participating hospitals (response rate, 100\%). Manuals regarding measures against exposure were used in four hospitals (Table 2). Conveyance of ACD injections after preparation was conducted by staff in charge of conveyance in four hospitals. Pharmacists in two hospitals, nurses in two hospitals, and nurse aids in one hospital were also engaged in conveyance work. All hospitals had original conveyance measures against exposure. Five hospitals used exclusive containers. Syringe caps and plastic bags were used in four hospitals each. A CSTD was used during ACD administration in patients in only one hospital. Medical staff in five hospitals used gloves during administration. Surgical masks were used in all hospitals, and goggles were used in one. Personal protective equipment (PPE) was exchanged before every patient treatment in four hospitals. Back-priming was carried out during administration in four hospitals. For measures regarding the administration route for ACD injections, gloves were used in one hospital and water-absorbing sheets were used in another. Regarding measures against exposure during ACD bottle exchange, gloves were used in all hospitals, surgical masks were used in five, and goggles were used in two.

\subsection{Measures against Exposure for Patients and Their Families after ACD Administration}

ACD bottles after administration were placed in sealed plastic bags at one hospital. Adhered ACDs were exhausted within sealed plastic bags and then 
Table 2. Survey on doctors and nurses about current conditions regarding measures against exposure druing administration of ACDs at outpatient services in 2012.

\begin{tabular}{|c|c|c|c|}
\hline \multirow{2}{*}{\multicolumn{2}{|c|}{ Question items }} & \multicolumn{2}{|c|}{$\mathrm{n}=6$ (Hospitals) } \\
\hline & & \multirow{2}{*}{$\begin{array}{c}\text { no. } \\
4\end{array}$} & \multirow{2}{*}{$\begin{array}{c}\% \\
66.7\end{array}$} \\
\hline Use of manuals of measure for exposure & & & \\
\hline \multirow{4}{*}{ Conveyer of ACDs after preparation ${ }^{*}$} & Staff in charge & 4 & 66.7 \\
\hline & Pharmacist & 2 & 33.3 \\
\hline & Nurse & 2 & 33.3 \\
\hline & Nurse aid & 1 & 16.7 \\
\hline \multicolumn{2}{|l|}{ Measures against exposure at conveyance of ACDs } & 6 & 100 \\
\hline \multirow{4}{*}{ Goods for use at conveyance of ACDs ${ }^{*}$} & Exclusive container & 5 & 83.3 \\
\hline & Syringe cap & 4 & 66.7 \\
\hline & Plastic bag & 4 & 66.7 \\
\hline & Other & 1 & 16.7 \\
\hline \multicolumn{2}{|l|}{ Use of CSTD at administration } & 1 & 16.7 \\
\hline \multirow{3}{*}{ PPE at administration* } & Surgical mask & 5 & 83.3 \\
\hline & Gloves & 6 & 100 \\
\hline & Goggles & 1 & 16.7 \\
\hline \multicolumn{2}{|l|}{ PPE exchange at administration for every patient } & 4 & 66.7 \\
\hline \multicolumn{2}{|c|}{ Back-priming of infusion line except with ACDs at administration } & 4 & 66.7 \\
\hline \multirow{3}{*}{ Measures when connecting or injecting ACDs } & Gloves & 1 & 16.7 \\
\hline & Water-absorbing sheet & 1 & 16.7 \\
\hline & Nothing special & 4 & 66.7 \\
\hline \multirow{3}{*}{ PPE for exchange of ACD bottles* } & Surgical mask & 5 & 83.3 \\
\hline & Gloves & 6 & 100 \\
\hline & Goggles & 2 & 33.3 \\
\hline \multicolumn{2}{|c|}{ Conveyance of ACDs within a sealed plastic bag after administration } & 1 & 16.7 \\
\hline \multicolumn{2}{|c|}{$\begin{array}{l}\text { Drug exhausion within a sealed plastic bag into a penetration-resistant } \\
\text { container }\end{array}$} & 3 & 50 \\
\hline \multicolumn{2}{|c|}{ Regulations for handling of linens for pateints administrated ACDs } & 0 & 0 \\
\hline \multirow{4}{*}{ PPE for dealing with excretions of patients* } & Surgical mask & 5 & 83.3 \\
\hline & Gloves & 6 & 100 \\
\hline & Goggles & 3 & 50 \\
\hline & Gown & 4 & 66.7 \\
\hline \multicolumn{2}{|c|}{ Guidance for patients or families regarding measures against exposure } & 5 & 83.3 \\
\hline
\end{tabular}

$\mathrm{ACD}$, anticancer drug; CSTD, closed-system drug transfer device; PPE, personal protective equipment; * multiple answers allowed. 
placed in penetration-resistant containers in three hospitals. Disposal of patient linens used in ACD administration were not regulated in any hospital. Gloves were the most frequently used measure against exposure for medical staff exposed to excretions of patients administrated ACDs. Surgical masks, goggles, and gowns were used in five, three, and four hospitals, respectively. Medical staff provided guidance for patients and their families regarding measures against exposure in five hospitals.

Survey regarding current conditions and problems related to chemotherapy in outpatients and measures against exposure in 2015.

\subsection{Background of Chemotherapy in Outpatients and ACD Preparation}

Current conditions for the medical staff concerning chemotherapy in outpatient departments were surveyed in all 10 of the participating hospitals (response rate, $100 \%$ ). Table 3 shows the number of beds used for chemotherapy in outpatient departments, the daily mean number of patients receiving chemotherapy, and the total number of nurses (Table 3). As part of outpatient services, ACDs were prepared for all cases receiving chemotherapy by hospital pharmacists. As part of inpatient services, ACDs were prepared for all cases by hospital pharmacists in eight hospitals. ACDs were prepared by doctors in five hospitals and by nurses in two.

\subsection{Measures against Exposure during Conveyance or Administration of ACDs}

Eight hospitals used CSTDs during ACD administration. The types of drugs used were cyclophosphamide (seven hospitals), bendamustine (six hospitals), and ifosfamide (four hospitals). Surgical masks and nitrile gloves were used as PPE during administration in all hospitals. Goggles were used in one hospital. PPE exchange was conducted for every patient in seven hospitals. Back-priming at administration was done in nine hospitals, and the types of ACDs used were cyclophosphamide, ifosfamide, bendamustine, bevacizumab, trastuzumab and pertuzumab. When connecting ACD infusion lines or preparing for intravenous administration, four hospitals took measures against exposure: two used cotton pads soaked with alcohol, and two used water-absorbing sheets. Ten hospitals took measures against exposure such as PPE use (five hospitals) and working in a low position (five hospitals) during ACD bottle exchange.

\subsection{Measures against Exposure after Administration of ACDs}

After administration, ACD bottles were placed in sealed plastic bags in eight hospitals. Adhered ACDs were exhausted within sealed plastic bags and placed in penetration-resistant containers in eight hospitals.

Comparison of results from 2012 and 2015 
Table 3. Survey on current conditions and measures against exposure at outpatient services in 2015.

\begin{tabular}{|c|c|c|c|}
\hline \multirow{2}{*}{\multicolumn{2}{|c|}{ Question items }} & \multicolumn{2}{|c|}{$\mathrm{n}=10$ (Hospitals) } \\
\hline & & \multirow{2}{*}{$\begin{array}{c}\text { Median } \\
614\end{array}$} & \multirow{2}{*}{$\begin{array}{c}\text { Range } \\
400-1275\end{array}$} \\
\hline Beds for inpatient service & & & \\
\hline Beds in the chemotherapy room at outpatient services & & 17 & $12.0-26.0$ \\
\hline Mean daily number of patients receiving chemotherapy & & 20 & $12.0-39.6$ \\
\hline \multirow{6}{*}{ Nurses } & Total & 4.25 & $3.0-9.0$ \\
\hline & Dedicated nurses & 3 & $1.0-8.0$ \\
\hline & Concurrent post nurses & 0 & $0-3.0$ \\
\hline & Part-time nurses & 0.5 & $0-2.0$ \\
\hline & Specialized nurses & 0 & $0-1.0$ \\
\hline & Authorized nurses & 1 & $0-3.0$ \\
\hline Number of patients treated by each nurse & & 4.7 & $3.1-5.8$ \\
\hline Number of patients for each bed & & 1.2 & $0.7-2.1$ \\
\hline \multirow[t]{2}{*}{ Number of beds treated by each nurse } & & 3.9 & $2.3-5.0$ \\
\hline & & no. & $\%$ \\
\hline Preparation for all patients by pharmacist at outpatient services & & 10 & 100 \\
\hline Preparation for all patients by pharmacist at inpatient services & & 8 & 80 \\
\hline Preparation by doctor in need & & 5 & 50 \\
\hline Preparation by nurse in need & & 2 & 20 \\
\hline Use of CSTD at administration & & 8 & 80 \\
\hline \multirow{3}{*}{ Type of drug* } & $\mathrm{CPA}$ & 7 & 70 \\
\hline & BEN & 6 & 60 \\
\hline & IFM & 4 & 40 \\
\hline \multirow{4}{*}{ PPE at administration* } & Surgical mask & 10 & 100 \\
\hline & Nitrile gloves & 10 & 100 \\
\hline & Latex gloves & 1 & 10 \\
\hline & Goggles & 1 & 10 \\
\hline PPE exchange at administration for every patient & & 7 & 70 \\
\hline \multirow[t]{2}{*}{ Back-priming of infusion line, except with ACDs, at administration } & & 9 & 90 \\
\hline & Cotton pads soaked with alcohol & 2 & 20 \\
\hline \multirow[t]{3}{*}{ Measures at connection or injection of ACDs with administration route } & Water-absorbing sheet & 2 & 20 \\
\hline & Nothing special & 5 & 50 \\
\hline & Use of PPE & 5 & 50 \\
\hline \multirow[t]{2}{*}{ Measures against exposure at ACD bottle exchange ${ }^{\star}$} & Work at low position & 5 & 50 \\
\hline & Other & 2 & 20 \\
\hline Conveyance of ACDs within a sealed plastic bag after administration & & 8 & 80 \\
\hline Drug exhausion within a sealed plastic bag into a penetration-resistent $\mathrm{cc}$ & & 8 & 80 \\
\hline
\end{tabular}

ACD, anticancer drug; BEN, bendamustine; CPA, cyclophosphamide; CSTD, closed-system drug transfer device; IFM, ifosfamide; PPE, personal protective equipment. ${ }^{*}$, multiple answers allowed, except for injection into the spinal space. 
The results for 10 survey items in 2012 were compared with those from 2015 (Table 4). In both years, pharmacists in most of the hospitals prepared ACDs of all inpatients and outpatients. The rate of wearing surgical masks or gloves as PPE during ACD administration was high both years; however, the rate of wearing goggles remained relatively low. No remarkable changes were observed in the rate of PPE exchange for every patient. The rates of use of CSTDs and back-priming of infusion lines, except with ACDs, were higher in 2015. The rate of measures against exposure during connection of infusion lines or ACD injections remained relatively low in 2015. During ACD bottle exchange, the rate of taking measures against exposure was $100 \%$ in both years. A higher number of hospitals placed and exhausted ACD bottles in sealed plastic bags and subsequently, penetration-resistant containers, after administration in 2015 compared with 2012 .

\section{Discussion}

We conducted a questionnaire survey regarding the current conditions against exposure to ACDs and compared the results between 2012 and 2015. In both years, ACDs were prepared by pharmacists in all hospitals. According to existing guidelines, one central section of the hospital is required for the preparation of ACDs [10], and medical staff engaged in ACD preparation should comprise pharmacists and either a doctor or a nurse with special training [11]. The guidelines recommend the use of class II type B2 BSCs as opposed to type A2 BSCs in

Table 4. Comparison of results from 2012 and 2015.

\begin{tabular}{|c|c|c|c|c|c|}
\hline & \multirow{3}{*}{ Question items } & \multicolumn{2}{|c|}{2012} & \multicolumn{2}{|c|}{2015} \\
\hline & & \multicolumn{2}{|c|}{$\mathrm{n}=8$ (Hospitals) } & \multicolumn{2}{|c|}{$\mathrm{n}=10$ (Hospitals) } \\
\hline & & no. & $\%$ & no. & $\%$ \\
\hline Preparation for all pati & harmacist at outpatient services & 7 & 87.5 & 10 & 100 \\
\hline \multirow{2}{*}{\multicolumn{2}{|c|}{ Preparation for all patients by pharmacist at inpatient services }} & \multicolumn{2}{|c|}{$\mathrm{n}=6$ (Hospitals) } & \multicolumn{2}{|c|}{$\mathrm{n}=10$ (Hospitals) } \\
\hline & & no. & $\%$ & no. & $\%$ \\
\hline \multicolumn{2}{|c|}{ Use of CSTD at administration } & 1 & 16.7 & 8 & 80 \\
\hline & Surgical mask & 5 & 83.3 & 10 & 100 \\
\hline PPE at administration & Goggles & 1 & 16.7 & 1 & 10 \\
\hline \multicolumn{2}{|c|}{ PPE exchange at administration for every patient } & 4 & 66.7 & 7 & 70 \\
\hline \multicolumn{2}{|c|}{ Back-priming of infusion line, except with ACDs, at administration } & 4 & 66.7 & 9 & 90 \\
\hline \multicolumn{2}{|c|}{ Measures for connection or injection of ACDs with administration route } & 2 & 33.3 & 4 & 40 \\
\hline \multicolumn{2}{|c|}{ Measure against exposure at ACD bottle exchange } & 6 & 100 & 10 & 100 \\
\hline \multicolumn{2}{|c|}{ Conveyance of ACDs within a sealed plastic bag after administration } & 1 & 16.7 & 8 & 80 \\
\hline \multicolumn{2}{|c|}{ Drug exhausion within a sealed plastic bag into a penetration-resistent container } & 3 & 50 & 8 & 80 \\
\hline
\end{tabular}

ACD, anticancer drug; CSTD, closed-system drug transfer device. 
ACD preparation [3] [5] [10] [11]. BSCs should be cleaned after the finish of daily work not by alcohol wiping, but also by wet wiping [12]. Based on the results of our survey, all hospitals used class II BSCs, and half of the hospitals performed wet wiping. Regarding preparations, the current conditions should be maintained.

Measures against exposure during ACD administration improved from 2012 to 2015. The medical costs of preparing ACDs in aseptic conditions after 2012 could be calculated, and manuals for the handling of ACDs were published in 2014 [12]; therefore, the rate of use of CSTDs or back-priming was considered to be higher in 2015 than in 2012. The use of CSTDs during ACD administration is recommended because leakage may occur during connection with or priming of the infusion line [4] [5] [11] [13]. It also reduces the contamination of infusion lines by cyclophosphamide, ifosfamide, and fluorouracil [14] in BSCs, on the floor, and in workstations [15]. Since the use of CSTDs in all occasions is difficult, it is desirable to carry out back-priming, which is a way of bypassing the main infusion route. Infusion tubes with lock-type connections or that cover part of the connection with gauze during exchange of ACDs are also important. The active use of CSTDs or back-priming might be important for exposure prevention.

In the handling of ACDs, including connecting or exchanging, PPE, including gloves, masks, gowns, and goggles, must be worn [4] [5] [11]. The use of masks and gloves at administration and the rate taking measures against exposure during ACD bottle exchange were high in both 2012 and 2015. Masks should be used for respiratory protection during ACD preparation, administration, and cleaning. N95 masks are recommended in principle because they have been shown to be more effective than surgical masks in regard to their filtering of aerosols and minute particles [4] [5] [11] [16]. Powder-free gloves made of nitrile rubber, latex, polychloroprene or polyurethane are recommended, and care must be taken to ensure that the gloves are not damaged; double-use is also suggested [3] [4] [5] [10] [11]. By contrast, gowns were only used in a few hospitals. Gowns should be worn whenever there is a risk of ACD exposure. Disposable, fiber-free, long-sleeve gowns with low osmolarity, a fastened front, and a zippered back are recommended [3] [4] [5] [10] [11]. As for other tools, goggles and face shields are used to protect the eyes and face from ACD exposure, as are hair and shoe covers [3] [10] [11]. Based on the results of this survey, surgical masks and gloves were used during administration and gowns were worn during preparation in all hospitals. Although the use of these tools is considered necessary, the costs can become high if N95 masks, goggles, and gowns are used at every administration, and this therefore needs to be taken into consideration. It is also important to remember to use expanded plastic or other proper containers for transporting ACDs after preparation to prevent leakage or breakage [5] [11].

The publication of manuals or guidelines was expected to be useful during conveyance and disposal of ACDs because the rates of conveyance and disposal of ACDs within sealed plastic bags after administration before being placed into 
penetration-resistant containers was markedly improved in 2015 from 2012 [12] [17]. Although the publication of a manual has been shown to improve the conveyance of ACDs within plastic sealed bags after administration [12], no special legal restrictions are currently in place for the abolition of contaminated ACDs or PPE in Japan. As realistic measures against exposure, abolitions should be placed into sealed plastic bags and then disposed in exclusive boxes for ACDs [3]. PPE should also be discarded in the same manner before hand washing with soap and water [4]. Abolition should be carried out using masks and gloves [4] [5]. However, each hospital needs to formulate their own regulations in relation to these and other problems, such as the handling of excreta, dirty linens, and body fluids. Currently, more cases are seen in which ACDs are administrated at home through central venous ports; therefore, measures against exposure should be provided in advance, similar to medical staff, to patients and their families to help prevent needless exposure.

To our knowledge, this is the first report concerning the actual conditions against exposure to ACDs in Japan. However, the present study does have some limitations. First, the sample size was small, which may have limited the interpretation of the data. We hope to conduct a subsequent study with a larger sample size in the future. Second, the present survey was conducted in core hospitals for cancer therapy, which raises the possibility that disparities between hospitals in Japan might not be adequately reflected. Third, the questionnaire method employed in the present study possesses a potential limitation in terms of the reliability of the measurements. We therefore compared survey results obtained at different times and found that the data were similar.

In conclusion, we report surveillance data regarding the current conditions of measures against ACD exposure in core hospitals for cancer chemotherapy in Japan. The findings illuminated difficulties in strictly following the guidelines, and suggested that the measurement of ACD exposure needs to be improved. Publishing appropriate manuals and providing adequate education for medical staff in every institution in Japan could be expected to improve this situation.

\section{Acknowledgements}

The authors would like to thank the medical staffs of FMOG-KYTOG for their contribution to patient diagnosis and treatment.

\section{Conflict of Interest Statement}

The authors declare that they have no conflict of interest.

\section{References}

[1] Stewart, B.W. and Wild, C.P. (2014) World Cancer Report 2014. World Health Organization Press, Geneva.

[2] Health and Social Statistics Division (2015) Vital Statistics, Statistics and Information Department Minister's Secretariat Ministry of Health, Labour and Welfare, Japan.

[3] ASHP (American Society of Health-System Pharmacists) (1990) ASHP Technical 
Assistance Bulletin on Handling Cytotoxic and Hazardous Drugs. American Journal of Health-System Pharmacy, 47, 1033-1049.

[4] NIOSH (National Institution of Occupational Safety and Health) (2004) NIOSH Alert. Preventing Occupational Exposures to Antineoplastic and Other Hazardous Drugs in Health Care Settings. NIOSH, Atlanta.

[5] ONS (Oncology Nursing Society) (2011) Safe Handling of Hazardous Drugs. 2nd Edition, ONS, Pittsburgh.

[6] Krepinsky, A., Bryant, D.W., Davison, L., et al. (1990) Comparison of Three Assays for Genetic Effects of Antineoplastic Drugs on Cancer Patients and Their Nurses. Environmental and Molecular Mutagenesis, 15, 83-92. https://doi.org/10.1002/em.2850150205

[7] Valanis, B.G., Vollmer, W.M., Labuhn, K.T. and Glass, A.G. (1993) Acute Symptoms Associated with Antineoplastic Drug Handling among Nurses. Cancer Nursing, 16, 288-295. https://doi.org/10.1097/00002820-199308000-00005

[8] Kopjar, N. and Garaj-Vrhovac, V. (2001) Application of the Alkaline Comet Assay in Human Biomonitoring for Genotoxicity: A Study on Croatian Medical Personnel Handling Antineoplastic Drugs. Mutagenesis, 16, 71-78.

https://doi.org/10.1093/mutage/16.1.71

[9] Jakab, M.G., Major, J. and Tompa, A. (2001) Follow-Up Genotoxicological Monitoring of Nurses Handling Antineoplastic Drugs. Journal of Toxicology and Environmental Health, 62, 307-318. https://doi.org/10.1080/152873901300018011

[10] OSHA (Occupational Safety and Health Administration) (1986) OSHA WorkPractice Guidelines for Personnel Dealing with Cytotoxic (Antineoplastic) Drugs. OSHA, Washington DC.

[11] ISOPP (International Society of Oncology Pharmacy Practitioners) (2007) Standards of Practice: Safe Handling of Cytotoxics. ISOPP, North Vancouver.

[12] Japanese Society of Hospital Pharmacists (2014) Manual of Preparations for Anti-Cancer Drugs. 3rd Edition, Japanese Society of Hospital Pharmacists, Jiho.

[13] ASHP (American Society of Health-System Pharmacists) (2006) ASHP Guidelines on Hazardous Drugs. ASHP, Bethesda.

[14] Sessink, P.J., Trahan, J. and Coyne, J.W. (2013) Reduction in Surface Contamination with Cyclophosphamide in 30 US Hospital Pharmacies Following Implementation of a Closed-System Drug Transfer Device. Hospital Pharmacy, 48, 204-212. https://doi.org/10.1310/hpj4803-204

[15] Sato, J., Mori, M., Kumagai, M., et al. (2012) Journal of Japanese Society of Hospital Pharmacists, 48, 441-444. (In Japanese)

[16] Davidson, C.S., Green, C.F., Gibbs, S.G., et al. (2013) Performance Evaluation of Selected N95 respirators and Surgical Masks When Challenged with Aerosolized Endospores and Inert Particles. Journal of Occupational and Environmental Hygiene, 10, 461-467. https://doi.org/10.1080/15459624.2013.818243

[17] Japan Society of Cancer Nursing (JSCN), Japan Society of Medical Oncology (JSMO) and Japan Society of Pharmaceutical Oncology (JASPO) (2015) The First Edition of JSCN/JSMO/JASPO Joint Guidelines for Safe Handling of Cancer Chemotherapy Drugs (Joint Guideline). (In Japanese) 
Submit or recommend next manuscript to SCIRP and we will provide best service for you:

Accepting pre-submission inquiries through Email, Facebook, LinkedIn, Twitter, etc. A wide selection of journals (inclusive of 9 subjects, more than 200 journals)

Providing 24-hour high-quality service

User-friendly online submission system

Fair and swift peer-review system

Efficient typesetting and proofreading procedure

Display of the result of downloads and visits, as well as the number of cited articles Maximum dissemination of your research work

Submit your manuscript at: http://papersubmission.scirp.org/

Or contact pp@scirp.org 